7. W.. Klyne, J. Biochem., 47, No. 4, xli (1950).

8. R. Tschesche, R. Kottler, and G. Wulff, Liebigs Ann. Chem., 699, 212 (1966).

\title{
SAPOGENINS OF Eryngium macrocalyx
}

M. T. Ikramov, I. A. Kharlamov,

R. L. Khazanovich, and Kh. Kh. Khalmatov

UDC $547.597+547.918$

Continuing a study of plants of the genus Eryngium L. (eryngo), we have isolated the total saponins from the roots of E. macrocalyx Schrenk. We used the procedure employed for isolating the saponins from the roots of E. octophyllum Eug. Kor. [1].

Acid hydrolysis of the saponins isolated gave the combined sapogenins. The sapogenins were separated on a column of silica gel, from which they were eluted with a mixture of chloroform and ethyl acetate with a gradient of increasing concentrations of ethanol (from 1 to 10\%). Two substances were obtained in the individual state. The first substance (mol. wt. 572), from its $R f$ values $[0.58$ in chloroform-ethyl acetate (2:1); 0.50 in benzene-chloroform-methanol $(3: 3: 0.5) ; 0.67$ in chloroform-methanol (11:1)] and melting point $\left(220-223^{\circ} \mathrm{C}\right)$, the melting point of its acetate $\left(113-116^{\circ} \mathrm{C}\right)$, its IR spectrum, and a mixed melting point, was identical with eryngiumgenin $\mathrm{A}$, which we have isolated previously from E. octophyllum [2].

The second substance was identified on the basis of its $R_{f}$ values, melting point, melting point of its acetate, and mass and IR spectra as oleanolid acid.

\section{LITERATURE CITED}

1. M. T. Ikramov, R. L. Khazanovich, and Kh. Kh. Khalmatov, Proceedings of a Jubilee Republican Scientific Conference of Pharmaceutists Devoted to the Fiftieth Anniversary of the Formation of the USSR fin Russian], Tashkent (1972), p.39.

2. M. T. Ikramov, R. L. Khazanovich, and Kh. Kh. Khalmatov, Khim. Prirodn. Soedin., 678 (1973).

Tashkent Pharmaceutical Institute. Translated from Khimiya Prirodnykh Soedinenii, No. 3, p. 401, MayJune, 1976. Original article submitted November 21, 1975.

This material is protected by copyright registered in the name of Plenum Publishing Corporation, 227 West 17 th Street, New York, N.Y. 10011. No part of this publication may be reproduced, stored in a retrieval system, or transmitted, in any form or by any means, electronic, mechanical, photocopying,
microfilming, recording or otherwise, without written permission of the publisher. A copy of this article is available from the publisher for $\$ 7$. So. 